\title{
Painful ophthalmoplegia from metastatic nonproducing parathyroid carcinoma: Case study and review of the literature
}

\author{
Marijke Eurelings, ${ }^{1}$ Catharina J.M. Frijns, and Frank J.F. Jeurissen \\ Department of Neurology (M.E., C.J.M.F.), and Department of Internal Medicine (F.J.F.J.), \\ University Medical Center, Utrecht, The Netherlands
}

Parathyroid carcinoma is an uncommon malignancy. Of the fewer than 400 cases reported, most have been cases of producing parathyroid carcinoma with accompanying hypercalcemia. Only 13 patients with nonproducing parathyroid carcinoma have been described. Nine of these 13 patients had metastatic disease. We report a patient with i.c. metastasis. Distal metastases of producing parathyroid carcinoma are treated surgically to prolong survival and prevent complications of hyperparathyroidism and hypercalcemia. One half of the patients with producing parathyroid carcinoma die within 5 years, mostly because of the complications of hypercalcemia. Nonproducing parathyroid carcinoma compares unfavorably with producing parathyroid carcinoma in terms of tumor progression and prognosis. Few data on choice of therapy in nonproducing parathyroid carcinoma are available. We treated our patient with a combination of radiotherapy and chemotherapy. Treatment was followed by an unexpectedly prolonged survival of 31 months after diagnosis of metastatic disease. Neuro-Oncology 4, 44-48, 2002 (Posted to Neuro-Oncology [serial online], Doc. 01-023, October 3, 2001. URL <neuro-oncology. mc.duke.edu>)

W e report a patient who had nonproducing parathyroid carcinoma with painful ophthalmoplegia from i.c. metastasis. We treated this patient with cranial radiotherapy $(5 \times 400$ cGy in 1 week) followed by 3 cycles of chemotherapy once every 3 weeks, with a combination of cisplatin $\left(100 \mathrm{mg} / \mathrm{m}^{2}\right.$ on day 1$)$ and etoposide $\left(120 \mathrm{mg} / \mathrm{m}^{2}\right.$ on days 1,2 , and 3$)$. In

Received 23 April 2001, accepted 8 August 2001.

${ }^{1}$ Address correspondence and reprint requests to Marijke Eurelings, Department of Neurology, University Medical Center, G03.228, P.O. Box 85500, 3508 GA Utrecht, The Netherlands. view of the extreme rarity of the tumor, clinical trials to test different treatment modalities are not feasible. Therefore, the development of future treatment strategies depends on anecdotal reports.

\section{Case Study}

A 45-year-old woman was treated for Graves' disease at another hospital. After 1 year she developed problems swallowing and speaking. Because of suspected thyroid carcinoma, a hemithyroidectomy was performed. Pathological examination showed a nonproducing parathyroid carcinoma (Fig. 1) (Schantz and Castleman, 1973; Vetto et al., 1993). Because the tumor was not radically removed, she received radiotherapy $(4000 \mathrm{cGy}$ at once followed by $6000 \mathrm{cGy}$ in fractions in 4 weeks at the tumor site). One year later, she presented with headache, vomiting, double vision, and a painful left eye. At examination, ptosis and abduction paresis of the left eye were found. A cerebral MRI scan showed an enhancing lesion in and around the cavernous sinus (Fig. 2A and 2B). The patient was treated with high-dose prednisolone, up to $80 \mathrm{mg}$ per day, because of a tentative diagnosis of Tolosa Hunt syndrome (Yousem et al., 1990). Because the symptoms and signs did not subside, lymphoma or metastatic tumor were suspected. On admission, she had a complete bilateral ophthalmoplegia with ptosis and absent pupillary light reflexes. Vision was unimpaired. Sensation was decreased bilaterally in the area of the first branch of the trigeminal nerve. No abnormalities were found during routine laboratory tests, which included tests for thyroid stimulating hormone, T4, calcium, and calcitonin. Cerebrospinal fluid examination repeatedly showed a slightly raised protein content of approximately $0.5 \mathrm{~g} / \mathrm{liter}$, a normal cell count, and no malignant cells. A cranial CT scan showed an enhancing lesion in the sellar region extend- 

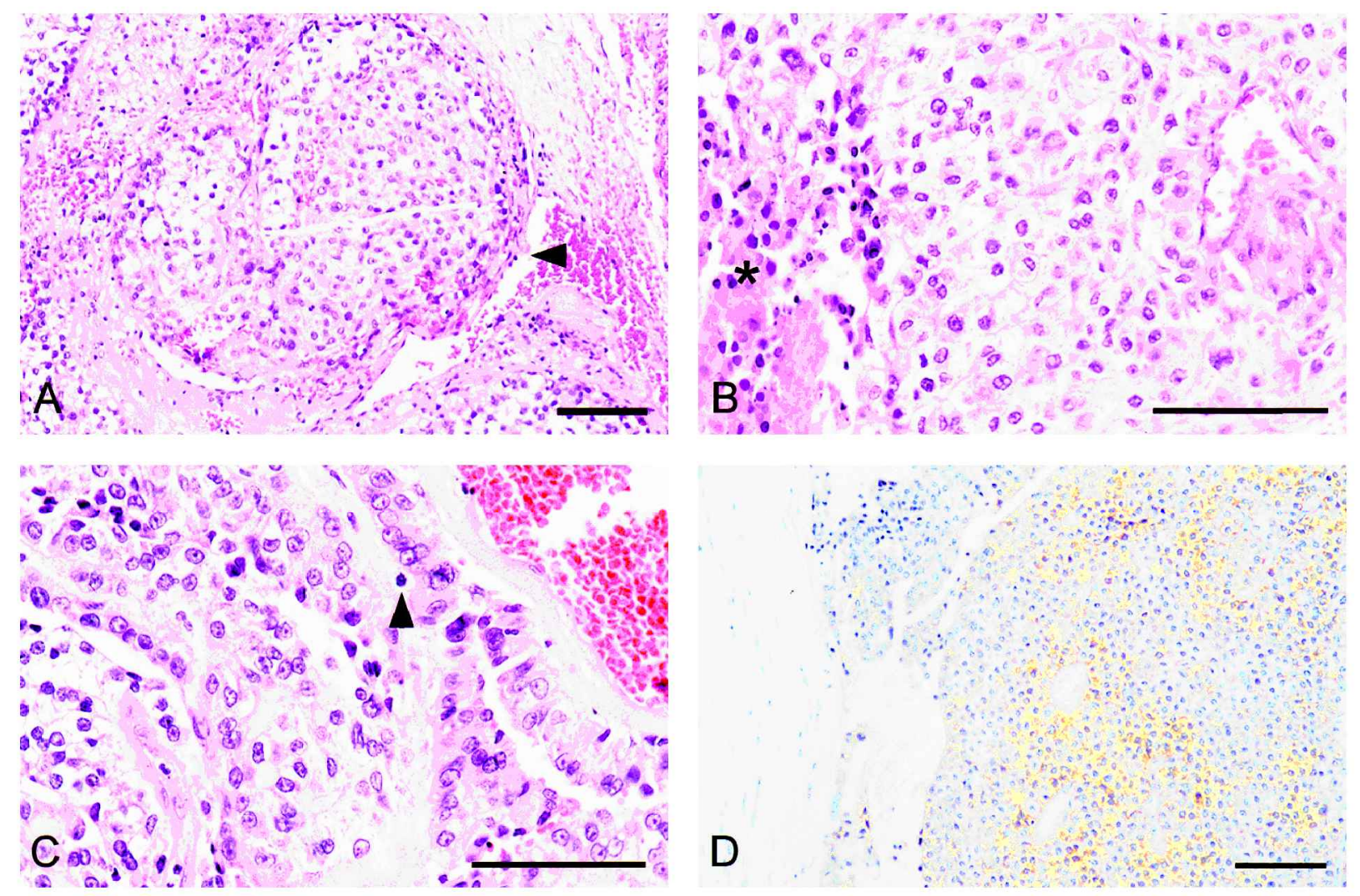

Fig. 1. Microscopy of the parathyroid carcinoma $($ bar $=100 \mu \mathrm{m}$ ). A. Vascular infiltration of tumor tissue (arrowhead; hematoxylin and eosin staining). B. Necrosis within the tumor (asterisk; hematoxylin and eosin staining). C. Anaplastic tumor areas with mitosis (arrowhead; hematoxylin and eosin staining). D. Tumor tissue consisting of clear cells showing positivity for neuro-endocrine marker chromogranin (brown staining).

ing into the cavernous sinus and around the carotid arteries, with central destruction of the sella. A CT scan of the chest showed bilateral multiple small lesions, which were probably metastatic. CT scan and ultrasound investigation of the abdomen were normal. Single-photon emission computed tomography scan showed increased octreotide labeling in the operated area of the thyroid, in the lower part of the lungs, and in the brain, matching the locations visible on the CT scans. Neurosurgical resection of the brain metastasis was considered impossible. Pathologic examination of the pulmonary lesions (obtained by thoracotomy) showed undifferentiated tumor tissue consisting of clear cells with neuroendocrine marks. The cells were positive for chromogranine and vimentine, negative for keratin and parathyroid hormone, identical to the tissue resected from the primary tumor. No other primary tumor was found, so the patient was diagnosed with i.c. metastasis and lung metastases of a nonproducing parathyroid carcinoma. Treatment was started with cranial radiotherapy $(5 \times$ 400 cGy in 1 week) followed by 3 cycles of chemotherapy once every 3 weeks, with a combination of cisplatin $\left(100 \mathrm{mg} / \mathrm{m}^{2}\right.$ on day 1) and etoposide $\left(120 \mathrm{mg} / \mathrm{m}^{2}\right.$ on days 1,2, and 3). Eight weeks after the last cycle of chemotherapy, ophthalmoplegia and ptosis of the right eye disappeared, and sensory function of the ophthalmic branches returned. On cerebral MRI scan, the bilateral lesions in and around the cavernous sinus had become less enhancing and slightly smaller (Fig. 2C and 2D). The lesions in the lungs had stabilized, and a mediastinal lymph node had become smaller. Seven months after initiation of treatment, ophthalmoplegia of the right eye recurred and the patient again developed sensory disturbances of the left upper part of her face. The patient lost weight and suffered from headache and nausea. She received a second dose of radiotherapy $(5 \times 400 \mathrm{cGy}$ in 1 week) and dexamethasone ( $4 \mathrm{mg} /$ day), but because of her poor general condition, we refrained from giving chemotherapy. Forty-five months after diagnosis of a nonproducing parathyroid carcinoma and 31 months after diagnosis of metastatic disease, the patient died of respiratory problems.

\section{Discussion}

Malignant, producing parathyroid tumors induce hypercalcemia, usually grow slowly, and metastasize relatively late (Koea and Shaw, 1999). The only curative treatment is en bloc resection (Flye and Brennan, 1981; Wynne et al., 1992). The few reports on nonproducing parathyroid carcinoma suggest a different disease with a more aggressive behavior (Table 1) (Aldinger et al., 1982; de Quervain, 1909; Guy, 1929; Hall and Chaffin, 1934; McQuillain, 1938; Mendiola, 1942; Merlano et al., 1985; Ordonez et al., 1983; Price and Mowat, 1932; Roffo and Landivar, 1914; Sieracki and Horn, 1960; Toland, 1931). The etiology of parathyroid carcinoma is unknown. It is 

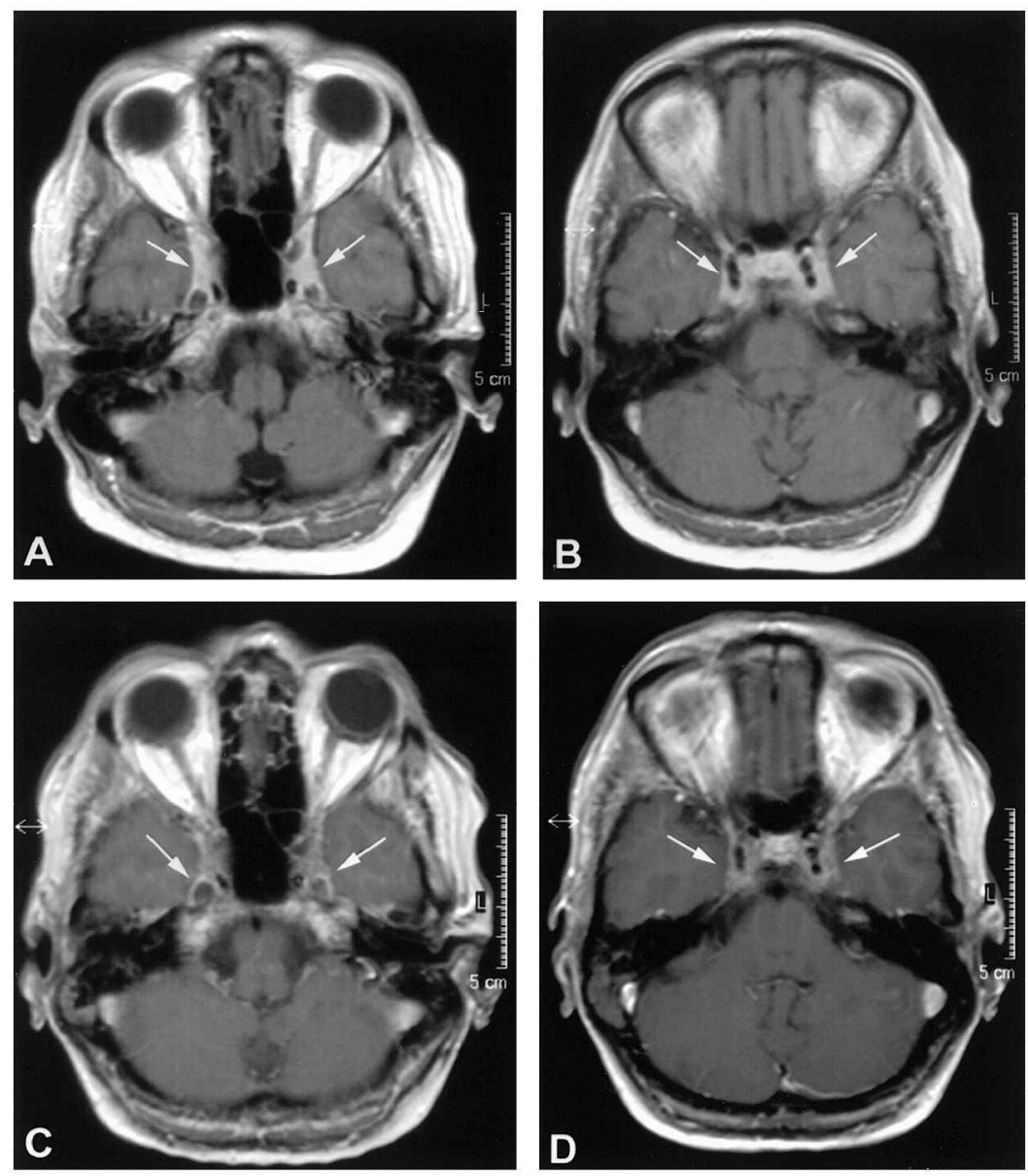

Fig. 2. Transversal T1-weighted MRI (enhanced with gadolinium) of the brain of a patient with metastasizing nonproducing parathyroid carcinoma. A and B. Profound enhancement and increased size of both the right and left cavernous sinus before treatment. C and D. Substantially diminished enhancement and somewhat smaller size of the cavernous sinus after treatment.

Table 1. Reported cases of nonproducing parathyroid carcinoma

\begin{tabular}{|c|c|c|c|c|c|c|c|}
\hline & Sex & $\begin{array}{l}\text { Age } \\
\text { (yrs) }\end{array}$ & $\begin{array}{c}\text { Local } \\
\text { invasion }\end{array}$ & $\begin{array}{l}\text { Local } \\
\text { recurrence }\end{array}$ & Metastases & Therapy $^{\mathrm{a}}$ & Survival (months) \\
\hline de Quervain, 1909 & $M$ & 68 & + & + & Lymph nodes, lungs, liver & Resection & Postoperative death \\
\hline Roffo and Landivar, 1914 & $M$ & 50 & NR & NR & Lymph nodes, lungs, liver & Resection & 2 \\
\hline Guy, 1929 & $\mathrm{~F}$ & 29 & NR & + & Lungs & Resection & $>30$ \\
\hline Toland, 1931 & $\mathrm{~F}$ & 60 & + & NR & Lungs & Resection & 4 \\
\hline Price and Mowat, 1932 & $M$ & 49 & + & + & Lungs & Resection & NR \\
\hline Hall and Chaffin, 1934 & $M$ & 50 & + & + & Lymph nodes, lungs & Resection & 36 \\
\hline Armstrong, 1938 & $\mathrm{~F}$ & 71 & + & NR & NR & Resection & NR \\
\hline McQuillain, 1938 & $\mathrm{~F}$ & 53 & + & + & NR & Resection, RT & $>28$ \\
\hline Mendiola, 1942 & $\mathrm{~F}$ & 32 & + & NR & NR & Resection & NR \\
\hline Sieracki and Horn, 1960 & $\mathrm{~F}$ & 43 & + & NR & - & Resection, RT & 36 \\
\hline $\begin{array}{l}\text { Aldinger et al., 1982; } \\
\text { Ordonez et al., } 1983\end{array}$ & M & 27 & NR & + & Lymph nodes, lungs, brain & Resection & 27 \\
\hline $\begin{array}{l}\text { Aldinger et al., 1982; } \\
\text { Ordonez et al., } 1983\end{array}$ & M & 59 & NR & NR & Lymph nodes, lungs, bones & $\begin{array}{l}\text { Resection, } \\
\text { adriamycin }\end{array}$ & 18 \\
\hline Merlano et al., 1985 & M & 59 & NR & NR & Lymph nodes, liver & RT & 16 \\
\hline Present study & $\mathrm{F}$ & 45 & + & - & Lungs, brain & $\begin{array}{c}\text { Resection, RT, } \\
\text { cisplatin/etoposide }\end{array}$ & 45 \\
\hline
\end{tabular}

Abbreviations: +, present; -, absent; NR, not reported; RT, radiotherapy.

${ }^{\mathrm{a}}$ Therapy of the primary tumor and metastases. 
possible that parathyroid carcinoma develops in parathyroid adenoma as a result of chronic stimulation (Sato et al., 2000). Somatic as well as germline mutations have been described in parathyroid carcinoma, and 5 families with parathyroid carcinoma have been reported (Kytola et al., 2000; Wassif et al., 1993). However, whether germline mutations or somatic mutations are specifically linked to the occurrence of nonproducing parathyroid carcinoma is not known because no data are available on this specific subject.

This is the second report of i.c. metastases of nonproducing parathyroid carcinoma (Aldinger et al., 1982). Also, 2 patients with i.c. metastases of producing parathyroid carcinoma have been reported (Tyler et al., 2001). Neuro-endocrine carcinomas metastasize very differently. Brain metastases are frequently found in patients with small cell-lung carcinoma (more than $30 \%$ of the patients), but brain metastases in parathyroid and thyroid carcinoma are rare. Only 6 patients with medullary thyroid carcinoma and brain metastases have been reported (Pitale et al., 1999). Two percent of all brain metastases are derived from unspecified neuro-endocrine carcinomas (Posner, 1995).

Producing and nonproducing parathyroid tumors are chemo- and radioinsensitive. After operation, only 3 of 13 patients with nonproducing parathyroid carcinoma received adjuvant therapy; 1 patient had no response to adriamycine; and 2 patients received radiotherapy postoperatively (Aldinger et al., 1982). Results of treatment of producing parathyroid carcinoma with vincristine and adriamycine were disappointing, but results of adjuvant radiotherapy were a cause for hope (Ordonez et al., 1983; Wynne et al., 1992). Therefore, based on 2 studies of treatment of neuro-endocrine carcinoma (Hainsworth et al., 1988; Moertel et al., 1991), we decided to treat our patient with a combination of radiotherapy and cisplatinum and etoposide. In contrast to reports in the literature, our patient showed an important improvement of her neurologic symptoms after receiving chemotherapy and radiotherapy. Moreover, MRI scans of the brain and CT scans of the lungs showed stable disease for a year.
We do not know whether the reported efficacy of the combined modality treatment in this patient holds true for all nonproducing parathyroid tumors or is related to the anaplastic pathologic features of this specific tumor. The primary tumor, as well as the lung metastases, consisted of undifferentiated tumor cells with neuroendocrine features. In contrast to well-defined malignant neuro-endocrine-producing tumors, anaplastic tumors with neuro-endocrine features have a significantly better response to chemotherapy (Moertel et al., 1991). Although an anaplastic pattern may sometimes be observed in a parathyroid carcinoma, these tumors have a rather uniform cell pattern (Schantz and Castleman 1973). In the report of Moertel et al. (1991), the well-differentiated neuro-endocrine tumors were $100 \%$ hormonally active, whereas the anaplastic variant was hormonally active in only $50 \%$ of cases. The background of the reported selective chemosensitivity of anaplastic tumors remains unknown. More studies of chemotherapy in nonproducing parathyroid carcinoma are necessary to develop a treatment strategy.

In conclusion, our patient showed a good clinical and radiologic response to the combination of chemo- and radiotherapy despite the reported chemo- and radioinsensitivity of the parathyroid tumors. In view of the dismal prognosis of metastatic, nonproducing parathyroid cancer, one should consider the possibility of combination therapy, especially in undifferentiated tumors.

\section{Acknowledgments}

We thank Dr. F. van Kooten, Department of Neurology, for the referral of the patients, and Dr. T. Manschot, Department of Pathology, for the pathologic material (both associated with Gelre Hospital, Apeldoorn, The Netherlands); Dr. G. Jansen, Department of Pathology, for the pathologic photographs, and Dr. T. Witkamp, Department of Radiology, for revision of the MRIs (both associated with University Medical Center, Utrecht, The Netherlands).

\section{References}

Aldinger, K.A., Hickey, R.C., Ibanez, M.L., and Samaan, N.A. (1982) Parathyroid carcinoma: A clinical study of seven cases of functioning and two cases of nonfunctioning parathyroid cancer. Cancer 49, 388-397.

Armstrong, H.G. (1938) Primary carcinoma of the parathyroid with report of a case. Bull. Acad. M. Toronto 11, 105-110.

de Quervain, V.F. (1909) Parastruma maligna aberrata. Deut. Zschr. Chir. 100: 334-352.

Flye, M.W., and Brennan, M.F. (1981) Surgical resection of metastatic parathyroid carcinoma. Ann. Surg. 193: 425-435.

Guy, C.C. (1929) Tumors of the parathyroid gland. Surg. Gynecol. Obstet. 48, 557-565.

Hainsworth, J.D., Johnson, D.H., and Greco, F.A. (1988) Poorly differentiated neuroendocrine carcinoma of unknown primary site: $A$ newly recognized clinicopathologic entity. Ann. Intern. Med. 109, 364-371.

Hall, E.M., and Chaffin, L. (1934) Malignant tumor of the parathyroid gland. West. J. Surg. 42, 578-586.

Koea, J.B., and Shaw, J.H. (1999) Parathyroid cancer: Biology and manage- ment. Surg. Oncol. 8, 155-165

Kytola, S., Farnebo, F., Obara, T., Isola, J., Grimelius, L., Farnebo, L.O., Sandelin, K., and Larsson, C. (2000) Patterns of chromosomal imbalances in parathyroid carcinomas. Am. J. Pathol. 157, 579-586.

McQuillain, A.S. (1938) Parathyroid tumor. Ann. Surg. 108, 464-468.

Mendiola, R. (1942) Parathyroid carcinoma. Rev. Mex. Cir. 10, 387-394.

Merlano, M., Conte, P., Scarsi, P., Tatarek, R., Barbieri, A., Santelli, A., Scarpati, D., and De Angelis, P. (1985) Non-functioning parathyroid carcinoma: A case report. Tumori 71, 193-196.

Moertel, C.G., Kvols, L.K., O'Connell, M.J., and Rubin, J. (1991) Treatment of neuroendocrine carcinomas with combined etoposide and cisplatin: Evidence of major therapeutic activity in the anaplastic variants of these neoplasms. Cancer 68, 227-232.

Ordonez, N.G., Ibanez, M.L., Samaan, N.A., and Hickey, R.C. (1983) Immunoperoxidase study of uncommon parathyroid tumors: Report of two cases of nonfunctioning parathyroid carcinoma and one intrathyroid parathyroid tumor-producing amyloid. Am. J. Surg. Pathol. 7, 535-542. 
Pitale, S.U., Melian, E., Thomas, C., Moley, J.F., Origitano, T., and Sizemore, G.W. (1999) Brain metastases from medullary thyroid carcinoma in a patient with multiple endocrine neoplasia type 2A. Thyroid 9, 1123-1125.

Posner, J.B. (1995) Intracranial metastases. In: Posner, J.B. (Ed.), Neurologic Complications of Cancer. Philadelphia: F.A. Davis. pp. 77-110.

Price, L.W., and Mowat, G.T. (1932) A case of rapidly-growing carcinoma in the neck, arising in a parathyroid rest. Br. J. Surg. 19, 645-650.

Roffo, A.H., and Landivar, Y.A.F. (1914) Case report. Prensa. Med. Argent. 2, 177-181.

Sato, M., Miyauchi, A., Namihira, H., Bhuiyan, M.M., Imachi, H., Murao, K., and Takahara, J. (2000) A newly recognized germline mutation of MEN1 gene identified in a patient with parathyroid adenoma and carcinoma. Endocrine 12, 223-226.

Schantz, A., and Castleman, B. (1973) Parathyroid carcinoma: A study of 70 cases. Cancer 31, 600-605.

Sieracki, J.C., and Horn, R.C., Jr. (1960) Nonfunctional carcinoma of the parathyroid gland. Cancer 13, 502-506.
Toland, C.G. (1931) Tumors of the parathyroid gland. J. Am. Med. Assoc. 96 741-744.

Tyler, D., III, Mandybur, G., Dhillon, G., and Fratkin, J. (2001) Intracranial metastatic parathyroid carcinoma: Case report. Neurosurgery 48, 937940.

Vetto, J.T., Brennan, M.F., Woodruf, J., and Burt, M. (1993) Parathyroid carcinoma: Diagnosis and clinical history. Surgery 114, 882-892.

Wassif, W.S., Moniz, C.F., Friedman, E., Wong, S., Weber, G., Nordenskjold M., Peters, T.J., and Larsson, C. (1993) Familial isolated hyperparathyroidism: A distinct genetic entity with an increased risk of parathyroid cancer. J. Clin. Endocrinol. Metab. 77, 1485-1489.

Wynne, A.G., Van Heerden, J., Carney, J.A., and Fitzpatrick, L.A. (1992) Parathyroid carcinoma: Clinical and pathologic features in 43 patients. Medicine 71, 197-205.

Yousem, D.M., Atlas, S.W., Grossman, R.I., Sergott, R.C., Savino, P.J., and Bosley, T.M. (1990) MR imaging of Tolosa-Hunt syndrome. AJR. Am. J. Roentgenol. 154, 167-170. 